\title{
Total Quality Transportation Through Deming's 14 Points
}

Bhimaraya A. Metri, Management Development Institute, India

\section{Abstract}

Transportation organizations, particularly public transport corporations, have not followed the lead of manufacturing or other service industries in adopting Total Quality Management (TQM). In recent years, quality has become an important competitive strategy in the global market. In near future, due to World Trade Organization agreements, globalization, and competitiveness, transport organizations have no choice other than adopting TQM for their survival.

This article presents a background on TQM and addresses the imperatives of using this strategy in transport organizations. The article examines total quality transportation (TQT) and its organizational structure and implementation model in relation to Deming's 14 points. The model presented in this research provides enhanced tactics for transportation quality and customer satisfaction.

\section{Introduction}

There is a great demand for transport facilities to meet the burgeoning needs of economic and social development (Zhang and Kumaraswamy 2001). In many developing countries including India, regional transit routes are operated by government agencies (Kalaga et al. 2001) and transport corporations (either state or municipal) to provide bus services in regional routes/metropolitan cities. Many transport systems in metropolitan cities of developing countries are facing pressure due to heavy immigration and increased industrial and commercial activities 
(Shrivastav and Dhingra 2001). A study carried out by Shrivastav and Dhingra (2001) revealed that the limited capacity of public road transport has led to an enormous increase in the use of private and intermediate transport services. Moreover, in many instances, public transport services are not coordinated with other modes, resulting in commuter dissatisfaction due to delays, longer journey times, poor levels of service, high vehicle operating costs, and environmental pollution. Given these circumstances, the research presented in this article suggests that, to improve customer satisfaction, public transport systems must offer more efficient services. The growing attention given to the role of public transit as a part of the transportation system creates an increasing need for transport agencies to measure and monitor the performance of the services they provide (Boile 2001). Boile (2001) called upon transport agencies to measure their performance in terms of accessibility, safety, mobility, financial effectiveness, and service efficiency. The best way to meet the needs of today's transport agencies is to replace the traditional Taylor approach with Total Quality Management (TQM). The transitions associated with implementing TQM are not always easy, smooth, or orderly. But, since the world is changing, transportation organizations do not have a choice; they must make a commitment to challenge traditional approaches or face obsolescence (Rubach 1995).

Many transport agencies still labor under the remnants of the departmentalized Taylor approach, in which some employees plan improvements, others carry out the work, and still others inspect the projects to determine whether procedures and results are correct. In contrast, under TQM, all employees commit to improving the quality of the organization's service so that customer needs are not only met but also exceeded.

\section{Background of TQM}

TQM is a structural system for creating organization-wide participation in planning and implementing a continuous improvement process that exceeds customer expectations. The Japanese concept of total quality control has come to be known as TQM. The name "Total Quality Management" was coined by the U.S. Navy in 1985 (Walton 1993). Since then, TQM has been widely used in various organizations, particularly in the manufacturing industry. Today, a variety of models are available to transform a current enterprise into an organization focusing on TQM. The foundations of TQM are rooted in the teachings of Dr. W. E. Deming (Burati et 
al. 1991). His 14 points model, which has been practiced successfully in Japan and the United States (Walton 1993), is considered here for the transport industry.

\section{Total Quality Transportation}

The term Total Quality Transportation (TQT) is used instead of TQM to shift attention away from preconceived notions of TQM and to focus on the commitment to provide quality transport service, promote learning skills, and encourage pride in workers' efforts to deliver service. TQT users subscribe to a customer-oriented transport service philosophy of continuous improvement that involves

- commitment to meet or exceed customer requirements,

- participation by critical mass of stakeholders,

- using statistical tools for analysis,

- continuous review of processes,

- exercising strong quality leadership,

- providing training and retraining programs,

- safety improvement,

- analysis of current performance,

- green transport system, and

- meeting local needs and regulations.

\section{Deming's Approach to TQT}

Deming's approach to TQM utilizes a 14-point process to create an organizational environment in which statistical methods will be effective. The 14 points are intended to create strong management commitment to quality, process design, and control through statistical tools, continuous search for and correction of quality problems, and a purchasing policy that emphasizes quality rather than cost. Further, this model is designed to remove all barriers to employee participation and teamwork. It stresses effective communication between supervisors and employees, elimination of numerical goals and quotas for employees, and company-wide training and education. This model also addresses the importance of product design and quality information systems. Deming's 14 points for TQT are described below. A graphical representation of the proposed model is presented in Figure 1. 


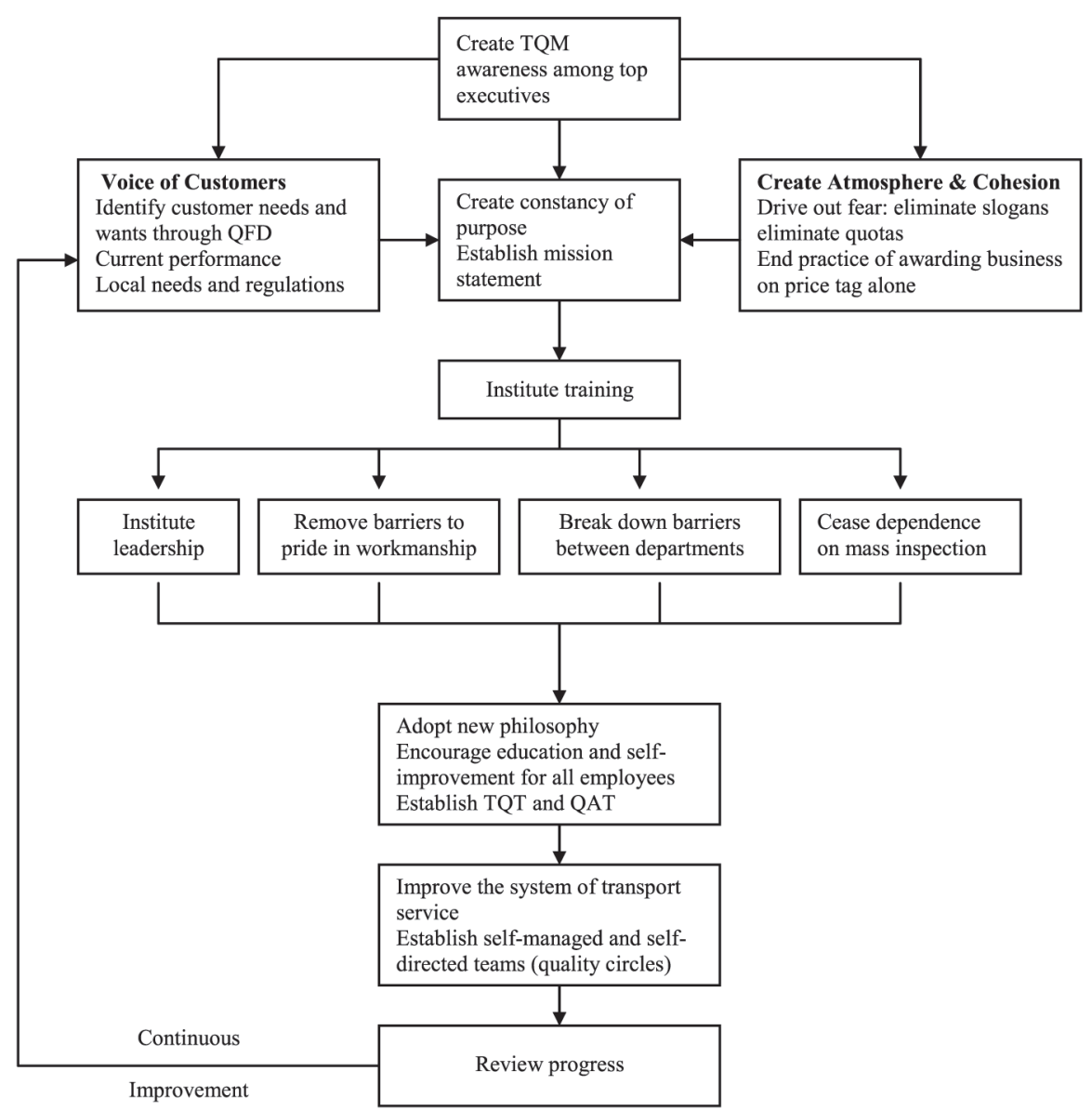

Figure 1. Proposed Model for Implementation of TQT

\section{Create Constancy of Purpose}

The customer is the most important part of transport service. Customer demands are always changing. It is mistake to presume that services offered at present can keep an organization solvent and ahead of competition. The transport agency must create a constancy of purpose by putting the customer first.

The transportation organization's highest priority must be to provide the best transportation services to its community at the lowest cost possible. The organization is responsible to both its community and its own workforce in maintaining a 
high level of excellence and value. Therefore, the transportation organization must strive to maximize efficiency and effectiveness through constant improvement.

To create a constancy of purpose necessitates the development of a mission statement for the transport corporation. The plan-do-check-act (P-D-C-A) cycle allows the statement to evolve as customer demand grows and changes. This flexibility permits innovation, which is achieved by putting resources into research, education, and maintenance of the transport system. Innovation generates new and improved services. For example, use of electric- and gas-based vehicles can reduce pollution in urban areas (Shridharan 2002). The corporate sector should lobby for electric-and gas-based vehicles for urban areas. A real concern is the availability of a wide network of service stations supplying gas or replacing discharged batteries with charged ones. Gas and battery industries can work together with the automakers industry to provide solutions with sustained business opportunities for themselves.

\section{Adopt New Philosophy}

In today's economic age, businesses cannot survive with commonly accepted levels of mistakes, defects, people on the job who do not understand the job and are afraid to ask questions, and management's failure to understand problems within the corporation.

Acceptable defective services and poor work performance are among the most severe roadblocks to better quality. Everyone working in a transport corporation can find ways to promote quality and efficiency, to improve all aspects of the transportation system, and to promote excellence and personal accountability. Employees, with the support of top management, should adopt a new work philosophy by meeting in cross-functional teams or quality circles to set priorities for staff training. The major benefit of the new philosophy is the creation of a continuous learning environment. The common thread in adopting a new philosophy is meeting the needs of those who pay for and use the services provided by the transportation organization.

\section{Cease Dependence on Mass Inspection}

Lasting quality comes not from inspection, but from improvements in the system. To achieve best economy and productivity, transport agencies should know what quality they are delivering. The organization's managers must be knowledgeable in the statistical control of quality. They must proceed under the new philosophy: the right service quality characteristics must be built in without dependence on 
inspection. The statistical control of the process provides the only way for transport operators to build quality service and the only way to provide managers evidence of uniform, repeatable quality and cost of service. One of the first steps for managers is to learn enough about the statistical control of quality to access the qualification of an operator by talking with them in statistical language.

\section{End the Practice of Awarding Business on Price Tag Alone}

Today's requirements for transport service suppliers are uniformity and reliability. Price has no meaning without a measure of quality. Without adequate measures of quality, business drifts to the lowest bidder, low quality and high cost being the inevitable results. Instead, the organization should seek the best quality in a long-term relationship with a single supplier for only one item. The results of implementing this strategy are longer lasting items and greater quality service at no additional cost. Transport agencies should select suppliers that can provide statistical evidence of quality. Since transport organizations tend to think of their suppliers as "partners" in their operations, they must consider joint planning for improvement and joint improvement activities to serve customers better than their competitors.

\section{Improve the System of Transport Service}

Quality can be built into all transportation activities and services and can be assured by continuous examination to identify potential improvements. This requires close cooperation between those who provide the services and those who consume them.

Improvement is not a one-time effort. Management is obligated to look continually for ways to reduce waste and improve quality. Every worker and every department must commit to constant improvement. Quality circles/cross-functional teams work together to improve transport service delivery. These groups may use basic quality tools to identify issues that need attention. For example, which faults are local and which ones belong to the system? The responsibilities should be given where this fault belongs. The use of statistical quality tools helps to identify trouble spots and their sources. Quality circles/teams continuously work to meet the needs of the people they serve, resulting in lower costs and improved quality of transport operations and services. Thus, improved transport service can result from focusing not only on achieving present performance levels, but more importantly, by breaking through existing performance levels to new, higher levels. 


\section{Institute Training}

Quality circles help the human resource division to select training programs that increase the job skills of both main and support staff. Training must be totally reconstructed. Statistical methods must be used to learn when training is finished and when further training would be beneficial. On-the-job quality improvement training ensures that every employee has a thorough understanding of customer needs for transport services.

\section{Institute Leadership}

The leader creates opportunities for all employees (good and bad performers) to interact and identify opportunities for improvement. The job of supervisor is not to tell employees what to do or to punish but to lead them toward better job performance. Leading consists of helping workers do a better job and of using learning by objective methods for those employees in need of individual help. Supervisors should be trained continually. They should receive training in synergetic or cooperative supervision and work in supportive teams to improve instructions and learning. Leadership training will help to introduce new best practices in transportation services to satisfy customer needs.

\section{Drive Out Fear}

Improved performance cannot occur unless employees in the transport organization feel comfortable to speak truthfully and feel confident that their suggestions will be taken seriously. Most workers are afraid to ask questions or to report trouble. Suggesting new ideas is risky; people fear punitive assignments or other forms of discrimination or harassment. To counter this fear, total quality encourages applying new methods, creating new solutions, and implementing innovative experiments. The economic loss from fear is appalling. To ensure better quality and productivity, employees must feel secure. In a secure environment, workers are not afraid to express ideas not afraid to ask questions, not afraid to ask for further instructions, and not afraid to report vehicles out of order, poor lighting, or other working conditions that impair quality service in transportation.

\section{Breakdown Barriers Between Departments}

According to Deming, people can work superbly in their respective departments, but if departmental goals conflict, the company could face ruin. Lack of coordination or disintegration between departments can lead to costly rework, unnecessary duplication of effort, and a heavy loss in resources. 
Quality Function Deployment (QFD) and quality circles improve cross-communication and encourage brainstorming among members of the transport organization. QFD helps to capture the "voice of the customer" and convert it into service design requirements. This strategy is not only a powerful tool for integrating departments of the transportation organization, but it also strongly promotes the principle of "do it right the first time" (Srividya and Metri 2000). Sharing a unified purpose and direction helps to improve the transport organization's services.

\section{Eliminate Slogans, Exhortations, and Targets for the Workforce}

Slogans, like those encouraging zero accidents or zero defects, and posters reinforcing the slogans do not help workers do a better job. Slogans, posters, and other such devices are management's lazy way out. A better approach is to provide the means to the desired ends. For instance, the transportation staff prevents waste and reduces accidents by managing its own quota-free environment. If the transport organization's focus is on improving its work processes, service quality will increase, efficiency and effectiveness will rise, and nonvalue-added activities will diminish.

\section{Eliminate Numerical Quotas}

Numerical quotas will not help workers do a better job. In fact, numerical quotas cost as much as loss in terms of poor materials and mistakes. In many factories at the end of the day, workers are idle the last hour or two. They have completed their quotas for the day and are waiting for the whistle to blow; they do no more work yet they cannot go to home. Numerical goals can even produce a negative effect because they generate frustration. Therefore, the quota system will not help the organization's competitive position or contribute to continuous improvement.

Instead of numerical quotas, hard work, pride, service, and growth should be emphasized. Removing quotas encourages employees to apply new ideas to old tasks. For instance, bus transportation schedules and stop locations are now planned to meet the community's needs. The goal is to fulfill the needs of the community, not to increase the number of people transported.

\section{Remove Barriers to Pride of Workmanship}

The transport industry cannot function properly without employees who are proud of their output and who feel respected as individuals and professionals. For example, inspection simply identifies defects but does not explain how to prevent them. Intrinsically, people want to provide service without defects. Leadership and continuous system improvement make this possible. To achieve pride in 
work, superiors must listen to the transport staff/employees and transport staff must listen to the recipients of their service (i.e., the community). Often, staff and community do not have the same knowledge base or purpose of work. Communicating the organization's mission and achieving respect among the staff and the community is one of the greatest challenges facing transport organizations.

\section{Encourage Education and Self-improvement for All Employees}

The transport organization needs not only good people, but people who are growing through education and life experiences as well. Both management and employees must continuously acquire knowledge to be of service to the community. They should be educated in new methods, including teamwork and statistical techniques. For instance, transport employees may receive training on ISO 14000 for providing environmental-friendly transport services to the community.

\section{Take Action to Accomplish Transformation}

The essence of TQT is an organization-wide focus on meeting the needs of those who use and/or pay for transport services. Every activity, every process, and every job in the transport organization can be improved. Everyone within the organization can be given an opportunity to understand the TQT program and their individual role within that effort. Improvement teams that include broad representation throughout the organization can help ensure success of initial efforts and create opportunities for cross-disciplinary dialog and information exchange.

Implementation of Deming's 14 points requires a special top management team, such as a quality council, with a plan of action to carry out the transport agency's quality mission. Workers or managers cannot accomplish this on their own. A critical mass of people in the organization must understand the 14 points. The critical mass would be formed from top down along the organizational hierarchical lines (Figure 2), and those involved would announce and define the new quality philosophy. Management teams called quality councils should take charge of changes in the system. They would be responsible for identifying and assigning the critical processes to the process quality teams (PQTs). In turn, the PQTs would direct the activities of the quality action teams (QATs). The QATs would focus on the critical issues, yielding some immediate results to show that TQT has worked. This tactic would help to strengthen and continue TQT in the transport organization.

At the same time, management would create a quality and cohesive environment and would also address such systematic issues as forging a new relationship with 
suppliers, doing away with the performance appraisal system, and introducing the "voice of customer" into all operations.

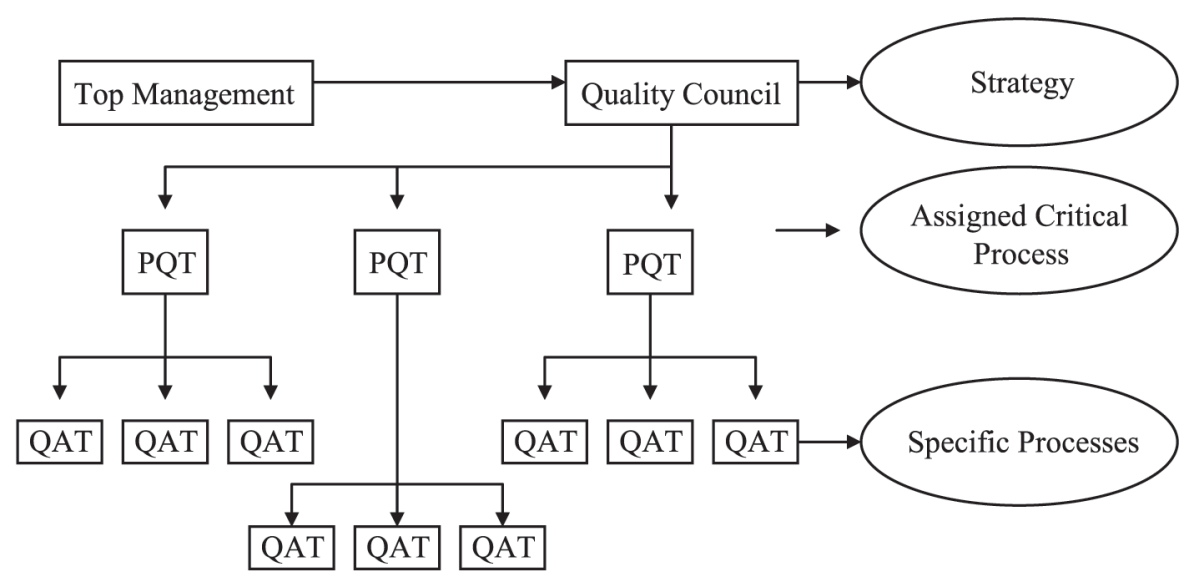

PQT: Process Quality Team QAT: Quality Action Team

\section{Figure 2. Organizational Structure for TQT}

\section{Conclusions}

This article has addressed the importance of TQM for transportation organizations. Total Quality Transportation (TQT) has been defined and Deming's 14point model has been presented for aiding TQT implementation. An organization structure and an implementation model have been proposed for immediate results of TQT and its successful implementation. The model is designed to guide top management in adopting TQT in their organizations.

Traditionally, transport organizations have been slow in adopting modern quality tools and techniques. Because of World Trade Organization agreements, in the near future, competitiveness will increase the demand for delivery of quality service in the transportation industry. TQT is a powerful strategy for improving quality. Due to global economic conditions, transportation organizations are at a crucial phase. Adoption of TQT is critical in helping organizations survive and compete in the growing international transport market. 


\section{References}

Boile, M. P. 2001. Estimating technical and scale inefficiency of public transit system. Journal of Transportation Engineering 127(3): 187-194.

Burati, J. L., M. F. Mathews, and S. N. Kalanidhi. 1991. Quality management in construction industry. Journal of Construction Engineering and Management 117(2): 341-359.

Kalaga, R. R., R. N. Datta, and S. K. Reddy. 2001. Allocation of buses in interdependent regional bus transit routes. Journal of Transportation Engineering 127(3): 208-214.

Rubach, L. 1995. Total quality forum VI speakers focus on changes. Quality Progress 28(2): 45-50.

Shridharan, L. 2002. Providing infrastructure needed: Paradigm shift in thinking. Yojana 46(2): 16-18.

Shrivastav, P., and S. L. Dhingra. 2001. Development of feeder routes for suburban railway stations using heuristic approach. Journal of Transportation Engineering 127(4): 334-341.

Srividya, A., and B. A. Metri. 2000. Improving reliability of building design using QFD approach. The Indian Concrete Journal 74(5): 249-253.

Walton, M. 1993. Deming management at work. New Delhi: Viva Books Private Ltd.

Zhang, $X$, and M. M Kumaraswamy. 2001. BOT-based approaches to infrastructure development in India. Journal of Infrastructure Systems 7(1): 18-25.

\section{About the Author}

BhimarayA A. MetrI (metri@mdi.ac.in) is associate professor of operations management at the Management Development Institute, Gurgaon, India. He holds a Ph.D. in quality management from the Indian Institute of Technology, Bombay. Dr. Metri's interests deal with total quality management and project management. He has published a number of papers in scholarly journals in the area of quality management. He is on the editorial board of the Journal on Consultancy. In addition, Dr. Metri supervises postgraduate research activity at the Ph.D. level. He has provided training/consultancy to several organizations in the areas of TQM, and he 
Journal of Public Transportation, Vol. 9, No. 4, 2006

has worked as a team member of the Principal Technical Agency (PTA) for PMGSY, Rural Road Projects in India. 